\title{
UMA ABORDAGEM PRELIMINAR DO SIGNWRITING COMO ALTERNATIVA PARA A ESCRITA DA LÍNGUA DE SINAIS
}

\section{A PRELIMINARY APPROACH TO SIGNWRITING AS AN ALTERNATIVE TO THE SIGN LANGUAGE WRITING}

Carla Damasceno de Morais

RESUMO: Este artigo propõe uma abordagem preliminar do sistema SignWriting, como alternativa para o registro das línguas de sinais. Por se tratar de um amplo sistema, compreendemos que a publicação de artigos por seções, seja uma estratégia eficiente de divulgar SW, que provavelmente seja utilizado em mais ou menos 62 países. A propósito da estratégia de publicações por seções, este artigo aborda: perspectiva expressiva, configurações de mãos básicas, alguns movimentos, dinâmicas de movimentos, algumas expressões não manuais, alguns pontos de articulação e o alfabeto manual. Para cada item abordado, quando possível, foram apresentadas quando há diferenças, as denominações de Capovilla, Raphael e Maurício (2009), Sutton (2001), Stumpf (2008) e Barreto e Barreto (2012). Após o quirema e sua função, foram apresentados sinais escritos em SW; entretanto, não é objetivo deste artigo impor um modelo de escrita. Concluímos que a divulgação deste sistema contribua para a sua consolidação como registro das línguas de sinais.

PALAVRAS-CHAVE: Língua de Sinais. SignWriting. Quiremas. Sinais escritos.

ABSTRACT: This paper proposes a preliminary approach to the SignWriting system as an alternative to the registration of sign languages. Because it is a comprehensive system, we understand that the publication of articles in sections is an efficient strategy to disseminate SW, which is likely to be used in more or less 62 countries. Regarding the strategy of publications by sections, this article deals with: expressive perspective, basic hands configurations, some movements, dynamics of movements, some nonmanual expressions, some points of articulation and the manual alphabet. For each item discussed, when possible, the names of Capovilla, Raphael and Maurício (2009), Sutton (2001), Stumpf (2008) and Barreto and Barreto (2012) were presented. After the quirema and its function, signs written in SW were presented; however, it is not the purpose of this article to impose a writing model. We conclude that the dissemination of this system contributes to its consolidation as a register of sign languages.

KEYWORDS: Sign Language. SignWriting. Quiremas. Written signs.

Submetido em: 08 out. 2018

Aprovado em: 31 out. 2018

\footnotetext{
i Doutora em Linguística Aplicada. Universidade Federal de Santa Catarina (UFSC). E-mail: moraiscarlasc@gmail.com.
} 


\section{Introdução}

Este artigo propõe uma abordagem preliminar do sistema SignWriting (SW) como alternativa para a escrita da língua de sinais. ${ }^{1} \mathrm{SW}$ efetua o registro das línguas de sinais de forma sequencial e com organização vertical da escrita, conforme exemplo abaixo.

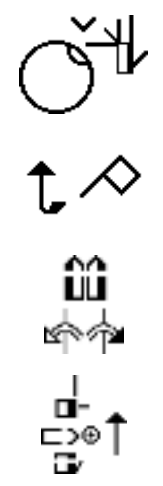

Tradução da autora: Amanhã vou comprar livro.

Por se tratar de um amplo sistema, compreendemos que a publicação de artigos por seções seja uma estratégia eficiente de divulgar SW que provavelmente seja utilizado em mais ou menos 62 países. Nesse sentido, este artigo aborda os seguintes tópicos: perspectiva expressiva, configurações de mãos básicas, alguns movimentos, dinâmicas de movimentos, algumas expressões não manuais, alguns pontos de articulação e o alfabeto manual. Para cada item abordado, quando possível, são postas, quando há diferenças, as denominações de Capovilla, Raphael e Maurício (2009), Sutton (2001), Stumpf (2008) e Barreto e Barreto (2012). Após cada item apresentado quanto à sua função na escrita em SW, sugerimos exemplos de escrita, no entanto, não é nosso objetivo impor um modelo de escrita.

\footnotetext{
1 SW não é o único sistema para escrever as línguas de sinais. Morais (2016) elaborou o capítulo intitulado Sistemas de Notação linear da língua de sinais e apresentou algumas pesquisas para registro da língua de sinais, iniciando por Roch-Ambroise Auguste Bébian (1789-1839), com a publicação do livro Mimographie ou Essais d'écriture mimique; a notação de Stokoe (1960), desenvolvida por William Stokoe; o SignFont (1986), desenvolvido por um grupo em San Diego; o HamNosys (1989) desenvolvido por pesquisadores de Hamburgo; o ELIS (2008), desenvolvido por Mariângela Estelita de Barros; e o SEL, desenvolvido em 2009 por Adriana Stella C. Lessade-Oliveira. Esses sistemas são alfabéticos e a escrita é linear.
} 
O SW foi desenvolvido por Valerie Sutton a partir de um sistema de notação de coreografia da dança - DanceWriting - também criado por ela. Apesar de ser uma invenção americana, o sistema foi usado inicialmente na Dinamarca e não está baseado em uma determinada Língua de Sinais (LS), podendo ser usado para escrever qualquer LS. Ele pertence à comunidade surda mundial e pode ser empregado por qualquer sinalizante (cf. CAPOVILLA; RAPHAEL, 2001). Segundo Sutton (2001, p. 21), "como a argila usada para criar uma estátua que perdurará por gerações futuras, o SignWriting pertence aos surdos para moldar sua própria Língua de Sinais, sua Cultura, sua História".

No Brasil, na Universidade Católica do Rio Grande do Sul, em 1996, os pesquisadores Antonio Carlos da Rocha Costa, Márcia Borda e Marianne Rossi Stumpf, desenvolveram um sistema computacional embasados no sistema de Valerie Sutton e lançaram a escrita SW pelo projeto SignNet. O sistema criado pelo referido projeto, o SW-Edit (2004), não está mais disponível. Atualmente os pesquisadores de SW utilizam o SignPuddle disponível em www.signbank.org/signpuddle para realizar a escrita da língua de sinais.

Em relação ao benefício e à importância deste sistema de escrita para a comunidade surda, Capovilla, Raphael e Maurício (2009, p. 46) compreendem que a escrita alfabética transcreve os fonemas que compõem a fala (unidades básicas das línguas faladas), a escrita em SW transcreve os quiremas que compõem a sinalização (unidades básicas das línguas de sinais). A escrita alfabética favorece o ouvinte porque ela transcreve os sons da fala que ele usa para pensar e comunicar-se oralmente. Já o SW beneficia o surdo pois transcreve as articulações e movimentos das mãos na sinalização que ele usa para pensar e comunicar-se em sinais.

O SW possui cerca de 35.000 mil quiremas, para representar as LS (BIANCHINI, 2012). É flexível, ou seja, a escrita de um sinal pode ser realizada de formas diferentes, dependendo da preferência do escritor. O SW representa configuração de mãos (CMs), ponto de articulação (PA), orientação de mão $(\mathrm{OM})$, movimentos (M) e expressões não manuais (ENM), considerados como parâmetros $^{2}$ das Línguas de Sinais.

\footnotetext{
2 Em 1960, o linguista William Stokoe, ao pesquisar a Língua Americana de Sinais (American Sign Language - ASL), identificou três parâmetros: configuração de mãos, ponto de articulação
} 
Avalia-se que a quantidade de representações de SW seja decorrente das diferenças de LS. Como no Brasil não utilizamos todas, provavelmente uma representação aqui empregada pode não ser útil na escrita em SW da língua de sinais de outro país. No entanto, suas representações e a função são padronizadas, o que permite que um sinalizante de determinado país entenda um sinal escrito em SW de uma língua de sinais diferente da sua. Essa possibilidade ocorre devido às orientações que constam em Lessons on Signwriting (SUTTON, 2001).

A maioria dos pesquisadores de SW, provavelmente, acompanham esse manual. Com o objetivo de demonstrar a padronização da função dos quiremas, organizamos no Quadro 1, o sinal escrito CASA na Libras, na Língua de Sinais Britânica e na ASL.

Quadro 1 - Sinal CASA

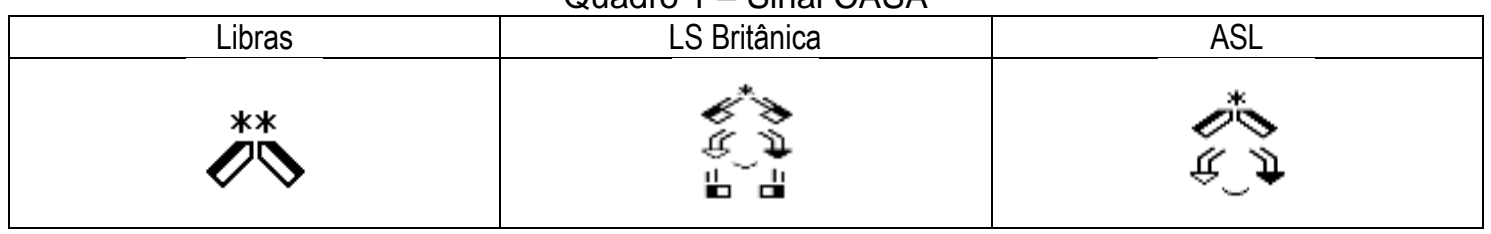

Fonte: www.signbank.org. Acesso em: 10 set. 2015.

Mediante a apresentação do Quadro 1 sobre a padronização da função dos quiremas na escrita, consideramos oportuno abordar, a seguir, a perspectiva expressiva, as configurações de mãos básicas, alguns movimentos, dinâmicas de movimentos, algumas expressões não manuais, alguns pontos de articulação e o alfabeto manual.

e movimento. Com a continuidade das pesquisas, Battison, em 1978 identificou mais dois parâmetros que se somaram aos três anteriores: orientação de mãos e expressões não manuais. 


\title{
2 Perspectiva expressiva, configurações de mãos básicas, alguns movimentos, dinâmicas de movimentos, algumas expressões não manuais, alguns pontos de articulação e o alfabeto manual
}

\subsection{Perspectiva expressiva e configurações de mãos básicas}

Nas orientações de Sutton (2001), a leitura e a escrita dos sinais são realizadas mediante nossa própria perspectiva, como se estivéssemos olhando para nossas próprias mãos. Barreto e Barreto (2012) consideram que, na perspectiva do observador, o sinalizante posiciona-se de frente para quem visualiza/observa os sinais. Portanto, os sinais da Libras em SW, são visualizados por meio da sua própria perspectiva. Nesse sentido, realiza-se a leitura dos sinais em SW neste artigo, na perspectiva do sinalizador (SUTTON, 2003, BARRETO; BARRETO, 2012) ou, conforme denominado por Capovilla, Raphael e Maurício (2009), na "perspectiva expressiva".

\begin{abstract}
A perspectiva expressiva, foi escolhida como padrão mundial para todas as publicações em SW pelo DAC, o Deaf Action Committee for SW (i.e. Comitê de Ação de Surdos em Prol do SW), um comitê de pessoas Surdas e sinalizadoras nativas. [...] foi escolhida porque os sinalizadores nativos expressam-se em sua própria língua. Ela é mais fácil de ler porque não requer do leitor o esforço de ter de ficar mudando mentalmente entre os lados direito e esquerdo. (CAPOVILLA; RAPHAEL; MAURÍCIO, 2009, p. 76).
\end{abstract}

Na perspectiva expressiva, a escrita em SW pode ser visualizada de dois planos: no plano vertical (plano parede) e no plano horizontal (plano chão). Os sinais são escritos conforme a CM, e podem ser visualizados: palma da mão, lateral da mão (palma/dorso) e dorso da mão. No Quadro 2, abaixo, apresentamse as orientações para os pontos de visão: 
Quadro 2 - Ponto de Visão das Orientações de mãos (OM) em SW

\begin{tabular}{|c|c|c|c|}
\hline \multicolumn{2}{|c|}{$\begin{array}{c}\text { CM pentá- } \\
\text { gono, } \\
\text { vertical. }\end{array}$} & Palma da mão & Lado da mão, palma/dorso. \\
\cline { 2 - 4 } $\begin{array}{c}\text { Plano pare- } \\
\text { de }\end{array}$ & Dorso da mão. \\
\hline $\begin{array}{c}\text { CM pentá- } \\
\text { gono, hori- } \\
\text { zontal. }\end{array}$ & $\begin{array}{c}\text { Palma para cima, com } \\
\text { espaço na junção dos } \\
\text { dedos. }\end{array}$ & $\begin{array}{c}\text { Palma para o lado } \\
\text { (palma/dorso) com espaço na } \\
\text { junção dos dedos. }\end{array}$ & $\begin{array}{c}\text { Palma para baixo, dorso, com } \\
\text { espaço, na junção dos dedos. }\end{array}$ \\
\hline
\end{tabular}

Fonte: Dados da pesquisa.

As CMs escritas em horizontal são paralelas ao chão e possuem um espaço na junção dos dedos. Os quiremas de CM básicas em SW são representados conforme o Quadro 3 abaixo:

\begin{tabular}{|c|c|c|}
\hline \multicolumn{3}{|c|}{ Quadro 3 - CM básicas em SW } \\
\hline \multicolumn{3}{|c|}{ CM básicas } \\
\hline & $\bigcirc$ & Pentágono Mão plana \\
\hline Quadrado Punho Fechado & Círculo Punho aberto \\
\hline
\end{tabular}

Fonte: Dados da pesquisa.

As CMs básicas, conforme Capovilla, Raphael e Maurício (2009), podem ser: quadrado (punho fechado), círculo (punho aberto) e pentágono (mão aberta ou plana). Os outros quiremas de CMs são variações. No Quadro 4, abaixo, apresenta-se a variação de CM, com base no Quadro 3, mostrado acima.

\section{Quadro 4 - Variações das CM básicas em SW}

\begin{tabular}{|l|l|l|}
\hline \multicolumn{3}{|c|}{ Variações das CMs básicas } \\
\hline \multicolumn{1}{|c|}{} & \multicolumn{1}{|c|}{ d } & \\
\hline $\begin{array}{l}\text { Quadrado, vertical, palma, o dedo } \\
\text { indicador estendido. }\end{array}$ & $\begin{array}{l}\text { Círculo, vertical, palma, o dedo } \\
\text { indicador estendido. }\end{array}$ & $\begin{array}{l}\text { Pentágono, palma, os dedos da } \\
\text { mão estendidos e separados. }\end{array}$ \\
\hline
\end{tabular}

Fonte: Dados da pesquisa.

Há 10 grupos para as CMs, agrupados de 1 a 10, sequência numérica realizada por Sutton (2003) e mediante a variação da CM da Língua Americana de Sinais (ASL), conforme mostrado no Quadro 5. 
Quadro 5-Grupo das CMs em SW

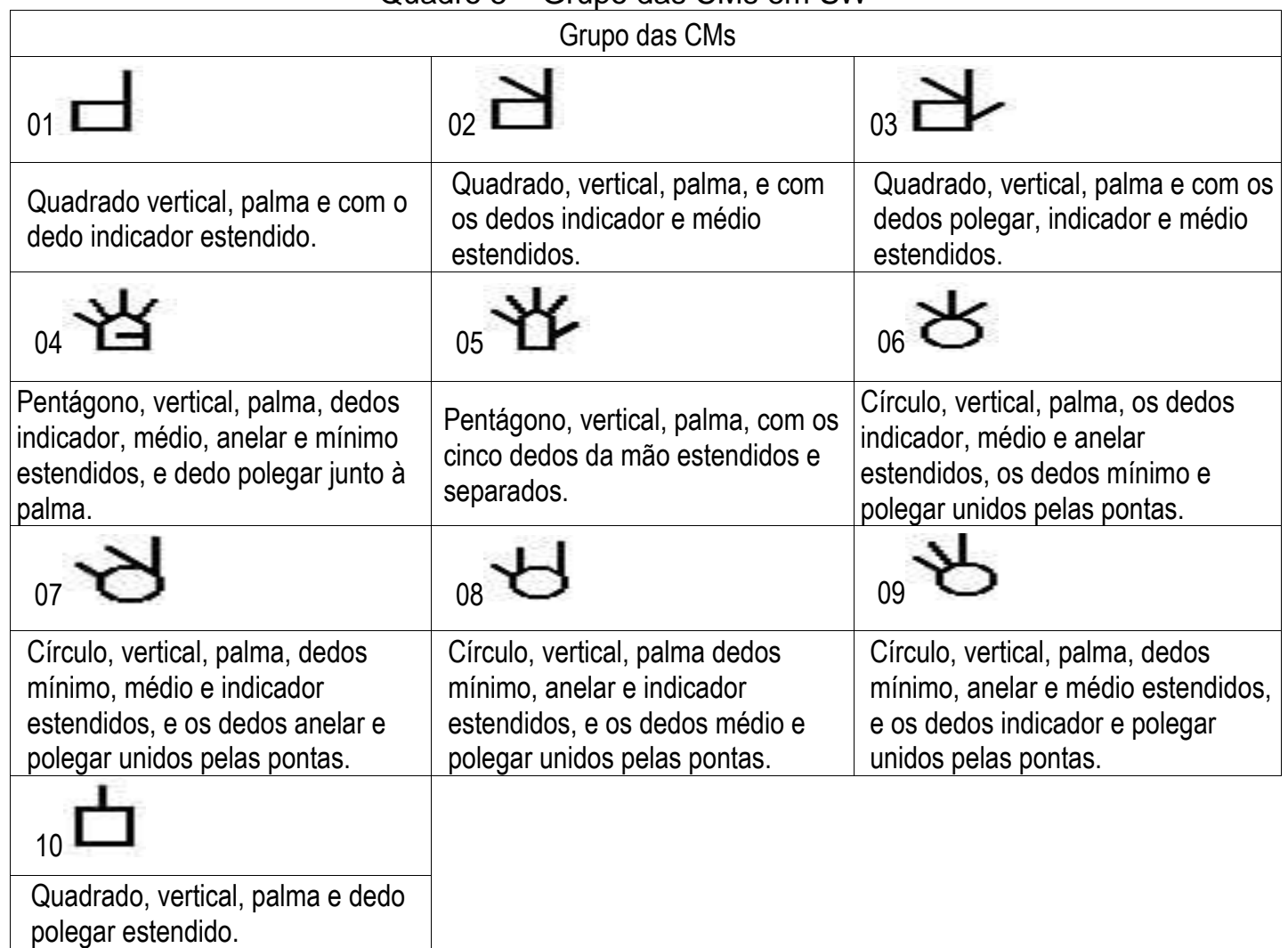

Com a abordagem da perspectiva expressiva, foi possível apresentar as configurações de mãos básicas e os grupos de configuração, uma vez que é a partir da compreensão desta perspectiva que o escritor/leitor de SW se orienta. Nesse sentido, abordaremos a seguir, os movimentos.

\subsection{Movimentos/contatos}

Alguns sinais da Libras incluem movimentos/contatos de mão com mão ou de mão com alguma parte do corpo. Sutton (2003) catalogou 6, apresentados no Quadro 6, abaixo.

Quadro 6 - Movimentos/contatos MC

\begin{tabular}{|c|c|c|c|}
\hline MC & Descrição & Função & Exemplo \\
\hline * & Asterisco/Tocar & $\begin{array}{c}\text { Toque suave de uma mão com a } \\
\text { outra ou outra parte do corpo. }\end{array}$ \\
\hline $\mathbf{6}$ & $\begin{array}{c}\text { Círculo com um ponto } \\
\text { centralizado /Escovar }\end{array}$ & $\begin{array}{c}\text { A mão se arrasta brevemente sobre } \\
\text { uma superfíie e depois se separa. }\end{array}$ \\
\hline CASA
\end{tabular}




\begin{tabular}{|c|c|c|c|}
\hline (c) & Espiral/Esfregar em Círculo & $\begin{array}{l}\text { M circular da mão e que se mantém o } \\
\text { contato na superfície; não é } \\
\text { necessário acrescentar seta de } \\
\text { movimento circular. }\end{array}$ & $\rightleftarrows_{\text {GOSTAR }}$ \\
\hline c & $\begin{array}{l}\text { Espiral/ } \\
\text { Esfregar } \\
\text { Linear }\end{array}$ & $\begin{array}{l}\text { Quando alocado junto com setas, } \\
\text { mantém o contato de uma mão com a } \\
\text { outra ou da mão com o corpo, e as } \\
\text { setas indicam o sentido do } \\
\text { movimento. }\end{array}$ & $0^{2} \sqrt{k^{2}}$ FACA \\
\hline & Adição/Pegar & $\begin{array}{l}\text { Indicativo de que a mão pega ou } \\
\text { segura uma parte do corpo ou da } \\
\text { roupa. }\end{array}$ & $\stackrel{\otimes}{+}$ \\
\hline & Cerquilha/Bater & $\begin{array}{l}\text { Uma mão bate na outra ou em uma } \\
\text { parte do corpo. Assemelha-se ao } \\
\text { contato tocar, no entanto, o toque é } \\
\text { forte. }\end{array}$ & $\nabla_{\text {DURISSIMO }}$ \\
\hline$|*|$ & $\begin{array}{c}\text { Contato entre. } \\
\text { Asterisco entre duas linhas } \\
\text { verticais. }\end{array}$ & $\begin{array}{c}\text { Indicativo de que o toque ocorre entre } \\
\text { duas partes do corpo (geralmente os } \\
\text { dedos). }\end{array}$ & $|*| \nabla$ \\
\hline
\end{tabular}

Fonte: Dados da pesquisa.

Barreto e Barreto (2012) sugerem que os movimentos/contato sejam alocados próximos de onde as mãos se tocam. Segundo os autores, não devem ser alocados entre duas CMs ou entre a mão e uma parte do corpo, a não ser em casos especiais (não especificados pelos autores). Stumpf (2005) sugere, como regra de grafia, a alocação do movimento/contato, indicando como corretos os sinais escritos à esquerda no Quadro 7 abaixo, e como incorretos, os sinais escritos no lado direito.

Quadro 7 - Alocação do contato

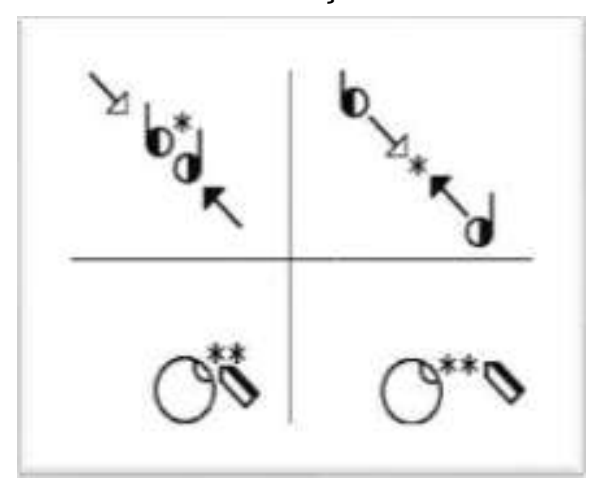

Fonte: Stumpf (2005, p. 64).

Observa-se que na escrita do sinal ENCONTRAR, em SW, alocada na primeira linha à esquerda do Quadro 7, o asterisco (movimento/contato tocar) foi alocado acima das CMs. O mesmo ocorre na escrita do sinal SABER, em SW, 
alocada na segunda linha à esquerda. Stumpf (2005) avalia que os sinais escritos à direita, não devem ser consideradas como escrita padrão.

\subsection{Movimentos (M)}

Nobre (2011) identifica os movimentos de dedos, de identificação do plano, direcionais e de mão e braço, abordados a seguir:

\subsubsection{Movimento de dedos}

Há sinais da Libras que ocorrem com movimentos de articulação de dedos, e estes se dividem em: falange distal (ponta do dedo), falange média (segunda falange) e falange proximal (última falange antes do metacarpo) (NOBRE, 2011). Os movimentos de dedos são denominados por Capovilla, Raphael e Maurício (2009) como movimento de dobradiça; Sutton (2003) denomina-os como movimento de articulação. Barreto e Barreto (2012), sugerem que as representações dos movimentos dos dedos sejam alocadas próximo ao dedo que realiza o movimento, conforme exemplos do Quadro 8.

Quadro 8 - Movimentos dos dedos

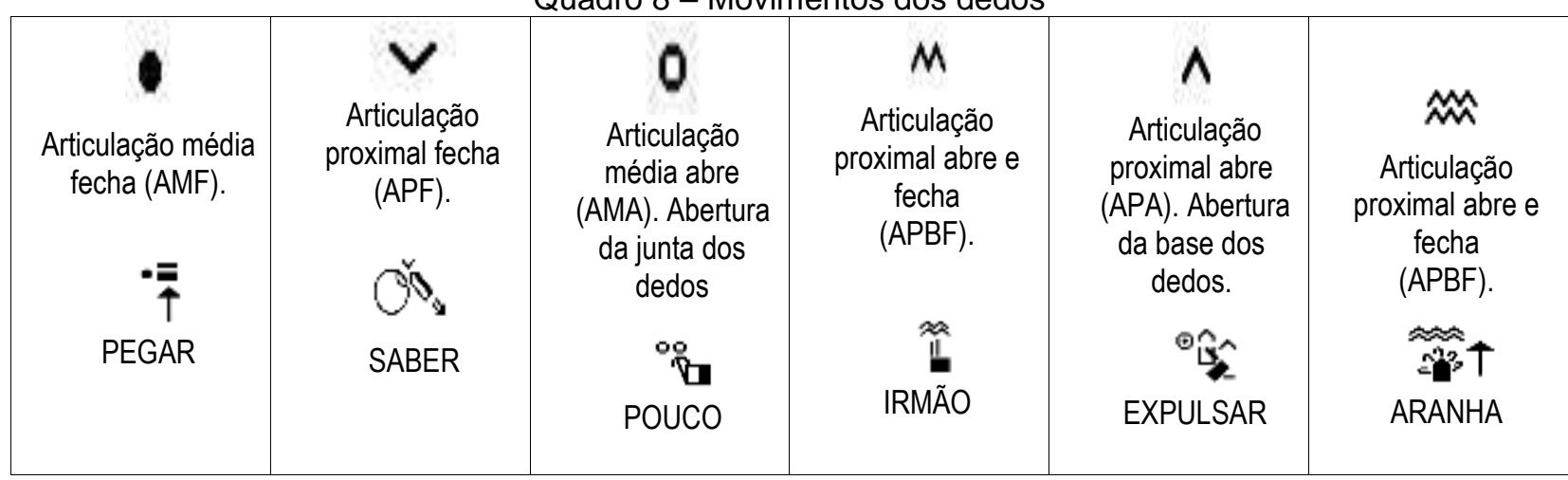

Fonte: Dados da pesquisa.

\subsubsection{Movimento (M) de identificação do plano}

Os sinais na LS são realizados num espaço de sinalização representado por SW no plano parede (vertical) e no plano chão (horizontal). Os movimentos 
verticais são representados por setas com duas hastes; quanto aos movimentos horizontais, são representados por setas com uma haste. Barreto e Barreto (2012), Capovilla, Raphael e Maurício (2009) e Sutton (2003), denominam a seta de duas hastes como "seta de haste dupla" e a seta de uma haste como "seta de haste simples". Elas são apresentadas no Quadro 9, abaixo.

Quadro 9 - Setas básicas

\begin{tabular}{|c|c|c|c|c|c|}
\hline \multicolumn{6}{|c|}{ Movimento de identificação dos planos } \\
\hline \multicolumn{3}{|c|}{ Plano vertical } & \multicolumn{3}{|c|}{ Plano horizontal } \\
\hline 开 & $\psi$ & $\pi$ & & & \\
\hline $\begin{array}{l}\text { M para } \\
\text { cima }\end{array}$ & $\begin{array}{l}\text { M para } \\
\text { baixo }\end{array}$ & $\begin{array}{c}\text { M para cima e para } \\
\text { baixo }\end{array}$ & $\begin{array}{l}\text { M para } \\
\text { frente }\end{array}$ & $\begin{array}{l}\text { Dois movimentos para } \\
\text { frente }\end{array}$ & $\begin{array}{c}M \\
\text { para trás e para } \\
\text { frente }\end{array}$ \\
\hline MAIS & 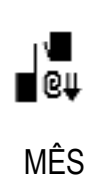 & 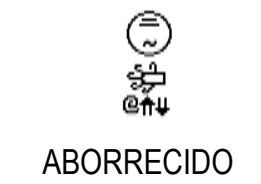 & VER & O QUE?? & $\stackrel{+\downarrow}{+1}$ \\
\hline
\end{tabular}

Fonte: Dados da pesquisa.

\subsubsection{Movimentos direcionais com sentido identificado}

Alguns sinais são articulados com as duas mãos e com movimento identificado por setas com haste simples ou haste dupla. A ponta da seta, com preenchimento preto, é indicativa de que se refere ao movimento da mão direita (Figura 1a); as setas com a ponta com preenchimento branco indicam que 0 movimento é realizado com a mão esquerda (Figura 1b).

Figura 1 - Setas para movimento das mãos direita (a) e esquerda (b)

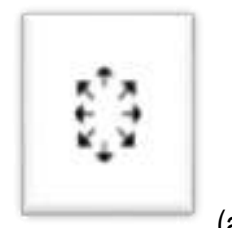

(a)

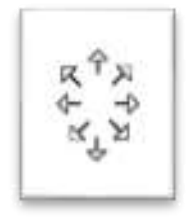

(b)

Fonte: Dados da pesquisa.

As figuras $2 \mathrm{a}$ e $2 \mathrm{~b}$, abaixo, apresentam as setas básicas de movimento no plano parede ou plano vertical. 
Figura 2 - Setas para movimento diagonais das mãos direita (a) e esquerda (b)
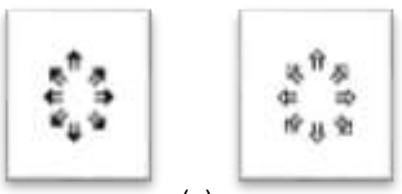

(a)

(b)

Fonte: Dados da pesquisa.

\subsubsection{Movimento em que dois planos se cruzam}

Há casos em que as setas de haste simples ou as setas de haste duplas são alocadas e que representam o mesmo movimento, conforme o Quadro 10:

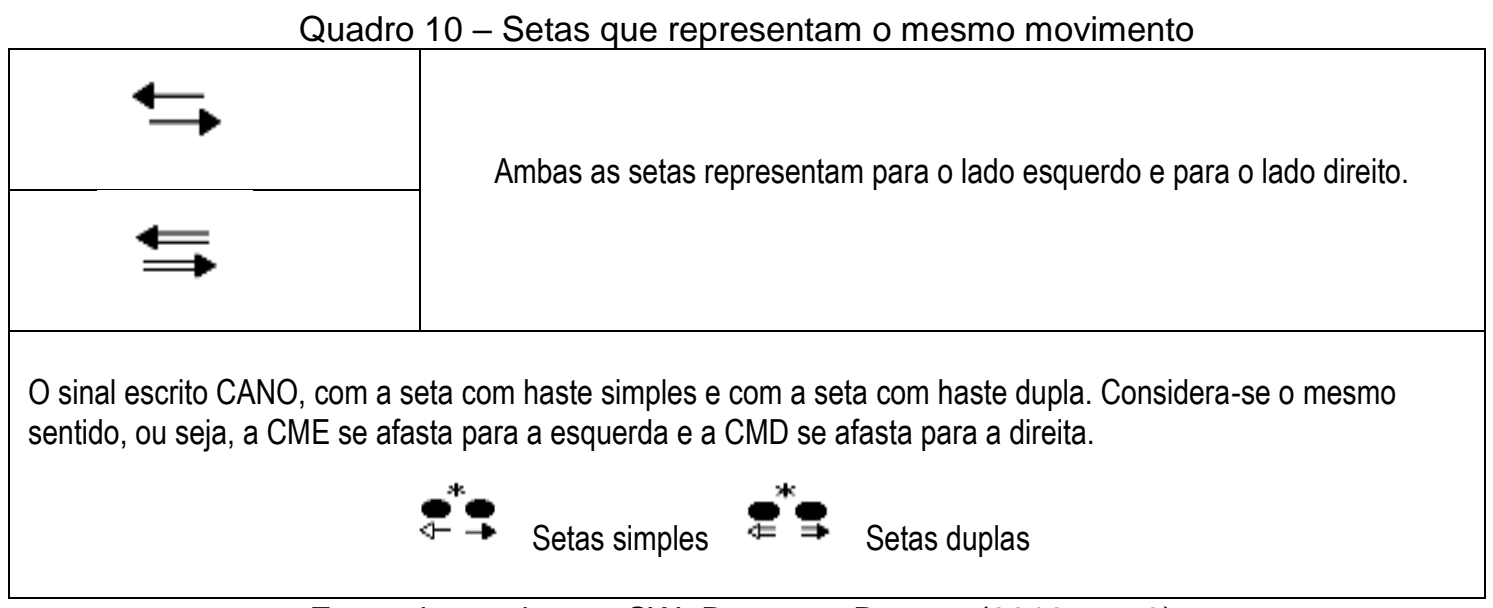

Fonte da escrita em SW: Barreto e Barreto (2012, p. 72).

\subsubsection{Movimento das mãos para a mesma direção}

As "pontas de seta geral" representam o percurso das mãos quando em contato uma com a outra, movimentando-se para a mesma direção. No entanto, as referidas setas também são utilizadas para sinais em que as mãos estão frente a frente, sem contato e se movimentam para a mesma direção (BARRETO; BARRETO, 2012, p. 73). Capovilla, Raphael e Maurício (2009, p. 96) sugerem a denominação da seta de "ponta aberta" e Sutton (2003, p. 121) denominou-a de "seta neutra". Elegemos para este artigo a denominação "ponta 
de seta geral". No Quadro 11, apresentamos as referidas setas, seguidas de exemplos.

Quadro 11 - Setas de ponta geral

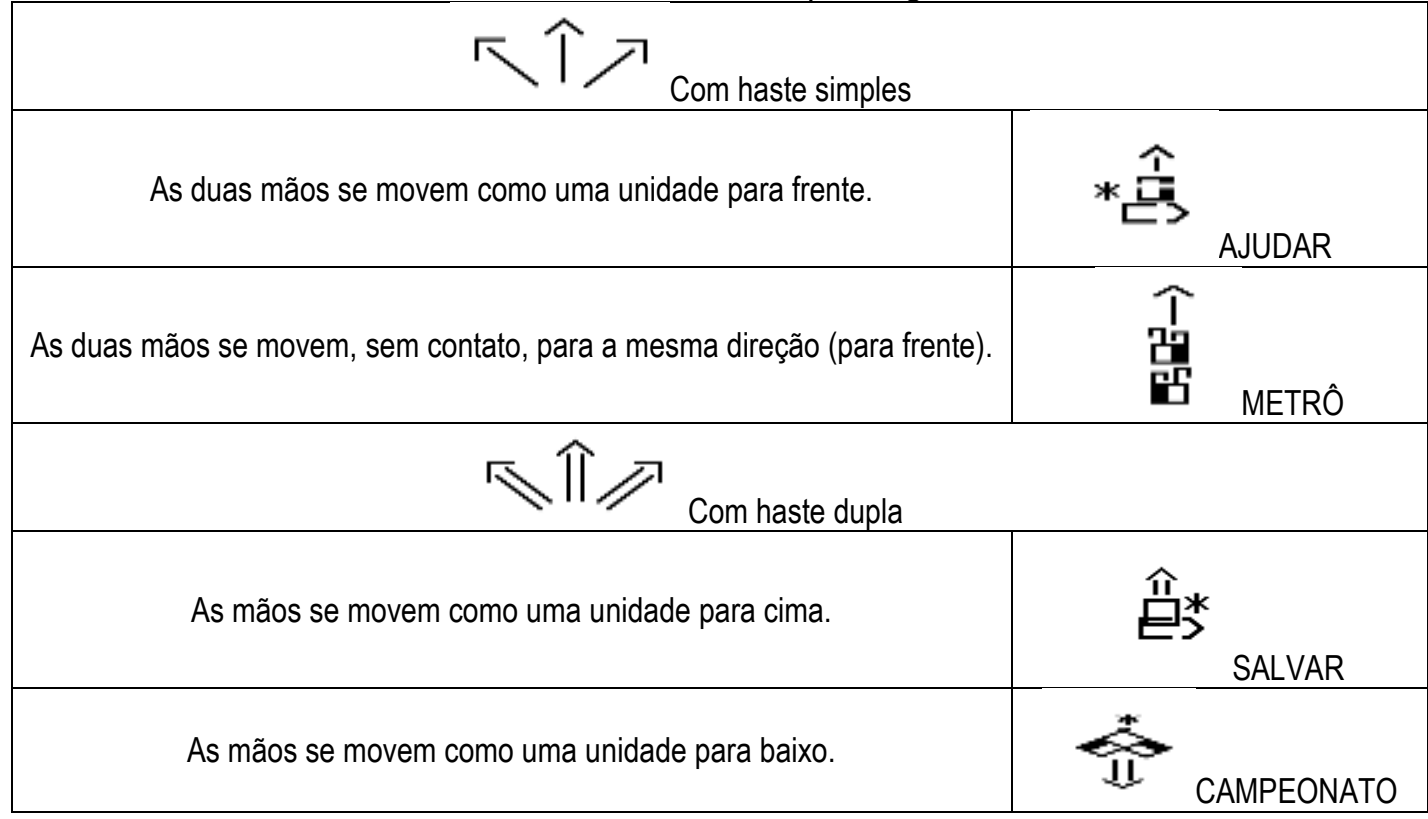

Fonte: Dados da pesquisa.

\subsubsection{Movimentos de mão e braço}

Barreto e Barreto (2012, p. 146) sugerem que a linha vertical que perpassa a seta de haste dupla representa o movimento do antebraço paralelo ao chão ou plano horizontal. No Quadro 12, os autores sugerem que as setas 1 e 2, sejam alocadas abaixo da CM, conforme escrita do sinal LIVRO; quanto às setas 3 e 4, podem ser alocadas acima ou abaixo da CM.

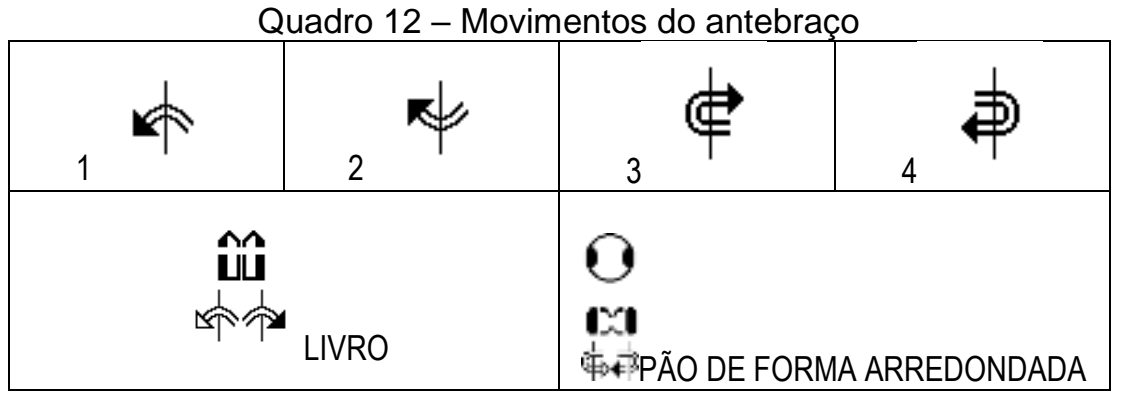

Fonte: Dados da pesquisa. 
No caso das setas básicas de rotação do antebraço, denominadas de haste simples, perpassadas por duas linhas verticais, representam o movimento do antebraço, paralelo à parede ou plano vertical. Barreto e Barreto (2012) sugerem que as setas 1 e 2 sejam alocadas abaixo da CM. Quanto às setas $3 \mathrm{e}$ 4, podem ser alocadas acima (escrita do sinal TEMPO) ou abaixo da CM (escrita do sinal CONGRESSO), como se pode ver no Quadro 13.

Quadro 13 - Movimento do antebraço - setas básicas de rotação de haste simples, perpassada por duas linhas verticais

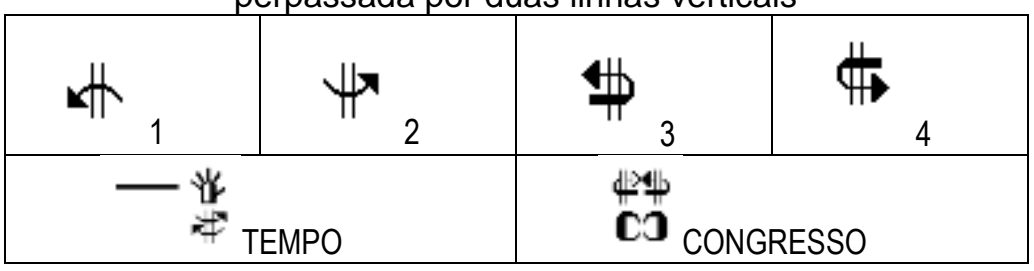

Fonte: Dados da pesquisa.

Apesar da sugestão dos autores de que a alocação das setas do sinal CONGRESSO seja acima das CMs, refletimos que como provavelmente se trata de movimento de rotação do antebraço, nesse sentido, conforme preferência do escritor, as setas podem ser alocadas abaixo das CMs.

\subsubsection{Movimento de giro/agito/vibração dos antebraços}

As sinalizações em que ocorre o movimento de giro/agito/vibração de 1 ou dos 2 antebraços, são chamadas por Barreto e Barreto (2012) de movimento de "giro/agito/vibração dos antebraços". Sutton (2003) denomina de movimento "tremendo".

Barreto e Barreto (2012, p. 149) sugerem que os movimentos do antebraço paralelo à parede frontal ou plano vertical (com duas linhas verticais perpassadas por três linhas convexas), "na maioria dos casos devem ser escritos na posição em que o antebraço está em relação à mão".

Nesse sentido, compreendemos que, no sinal DÓLAR (Quadro 14), a representação de giro/agito/vibração, alocada abaixo da $\mathrm{CM}$, substitui 0 antebraço (não visível). 
Quadro 14 - Giro/Agito/Vibração do antebraço no plano vertical

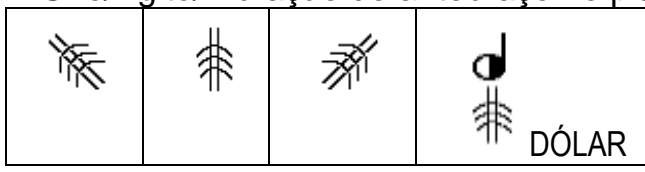

Fonte: Dados da pesquisa.

A alocação do movimento do antebraço paralelo ao chão, ou plano horizontal (representação com uma linha vertical perpassada por três linhas convexas), abaixo da CM, conforme exemplo do Quadro 15, segue a mesma base teórica para a escrita do sinal DÓLAR, acima. Analisa-se que na escrita do sinal MAIS OU MENOS, a representação de giro/agito/vibração, alocada abaixo da CM, substitui o antebraço (não visível).

Quadro 15 - Giro/Agito/Vibração do antebraço no plano horizontal

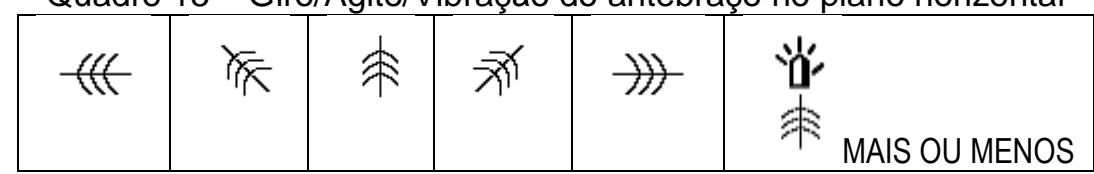

Fonte: Dados da pesquisa.

\subsubsection{Movimentos circulares da mão e do antebraço}

Nos movimentos circulares da mão e do antebraço, 4 (4) a ponta da seta indica o lugar, o início, a direção, e a quantidade do movimento (uma seta representa um movimento; duas setas representam dois movimentos). A haste é mais grossa quando a mão está próxima do corpo, e a haste é mais fina quando a mão se afasta do corpo. Observa-se, no Quadro 16, que as setas estão alocadas abaixo da CM que se movimenta.

Quadro 16 - Setas de movimentos circulares

\begin{tabular}{|c|c|c|c|c|}
\hline (G) & (1) & (5) & $\begin{array}{l}\text { Plano 1. Movimento circular plano } \\
\text { vertical. }\end{array}$ & USAR \\
\hline$\leftrightarrow$ & 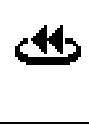 & $\overrightarrow{\mathbf{P}}$ & $\begin{array}{l}\text { Plano 2. Movimento circular plano } \\
\text { horizontal. }\end{array}$ & $\stackrel{\text { ウ }}{{ }_{\text {AZEITE }}}$ \\
\hline 9 & Q & 7 & $\begin{array}{l}\text { Plano 3. O movimento da mão e do } \\
\text { braço é semelhante a remar um barco. }\end{array}$ & 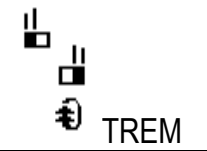 \\
\hline
\end{tabular}

Fonte: Dados da pesquisa. 


\subsubsection{Movimento de flexão do pulso}

As representações para o movimento de flexão do pulso (SUTTON, 2003) ou movimentos retos (BARRETO; BARRETO, 2009) são encontradas nos sinais escritos em que somente a mão se move pelo pulso, para frente, para trás, para cima e para baixo, nesse caso, o antebraço não acompanha o movimento. As setas são escritas com uma linha horizontal (representação do pulso), acima da(s) haste(s) e são alocadas, segundo Barreto e Barreto (2012), próximas ao pulso. Apresenta-se, no Quadro 17, algumas setas, seguidas de exemplos de escrita.

Quadro 17 - Movimentos de flexão do pulso

\begin{tabular}{|c|c|c|c|c|c|c|c|}
\hline Para baixo & 口点 & Para cima & T표묘 & Para trás & = 显 & Para os lados & $\Delta \mid \underset{\rightarrow}{\rightarrow}$ \\
\hline $\bar{\Downarrow}$ & ATRASAR & IIII & $\begin{array}{l}\text { FISGAR O } \\
\text { PEIXE }\end{array}$ & 士 & мOTO & & SINO \\
\hline
\end{tabular}

Fonte da escrita em SW: Barreto e Barreto (2012, p. 195).

\section{Dinâmicas do movimento}

Representações específicas são alocados para as dinâmicas de movimento das mãos: simultâneo; uma mão se move e a outra permanece imóvel; tenso; alternado; lento; rápido; relaxado. O Quadro 18, elaborado por meio do referencial teórico de Stumpf (2014), Barreto e Barreto (2012) e Sutton (2003), apresenta dinâmicas de movimento com exemplos de sinais escritos em SW. 
Quadro 18 - Dinâmicas de movimento

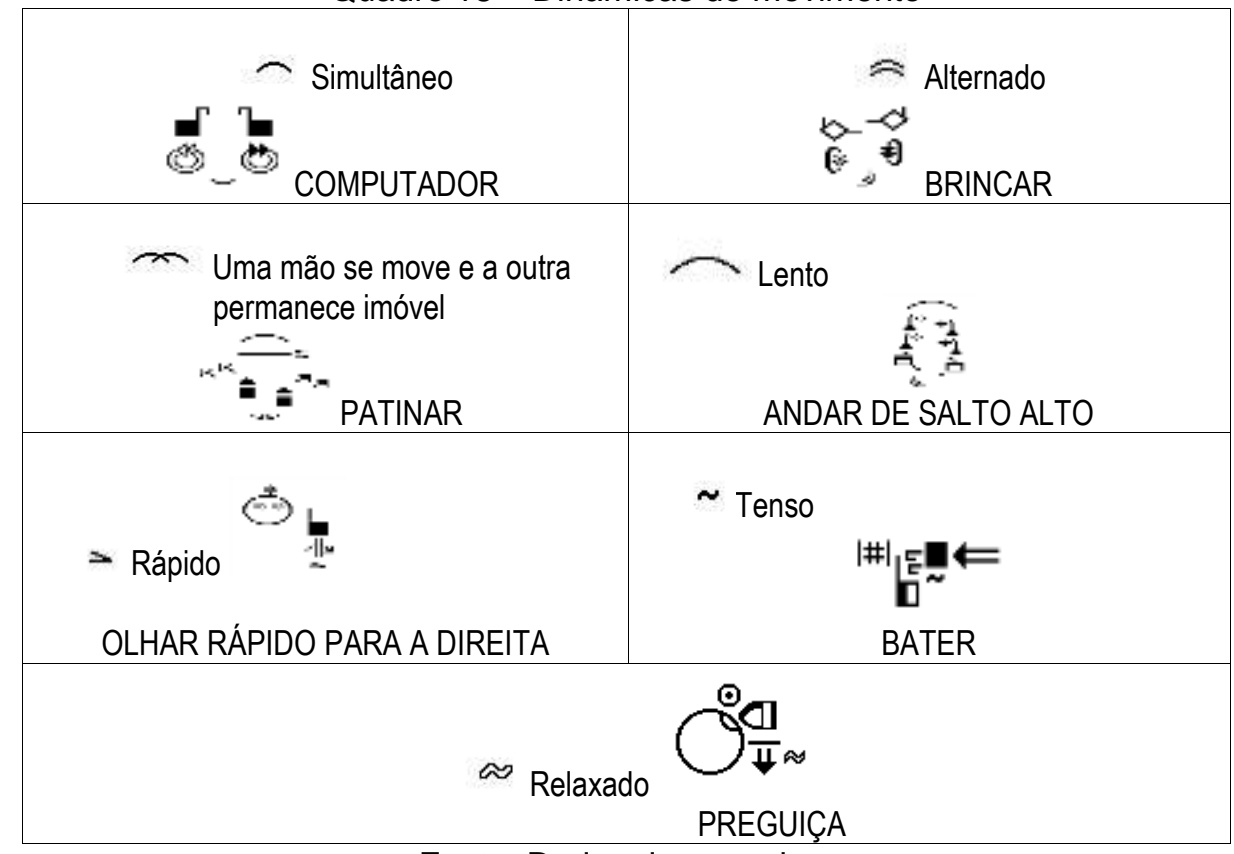

Fonte: Dados da pesquisa.

Observa-se, no Quadro 18, acima que, no sinal escrito COMPUTADOR, com o Movimento Simultâneo (MS), as CMs estão paralelas e espelhadas e o MS está alocado abaixo das setas de movimento circular. No sinal escrito BRINCAR, com o movimento alternado (MA), as CMs estão espelhadas, mas não estão paralelas (a CME está um pouco abaixo da CMD), e o MA está alocado abaixo das setas de movimento circular. Barreto e Barreto (2012, p. 62) compreendem que não seja necessário escrever o componente do MS, tendo em vista que se alocam, junto às $\mathrm{CMs}$ e aos movimentos/setas. Quanto à alocação do MA, os autores sugerem que as CMs devem ficar levemente deslocadas. Quanto aos demais movimentos de dinâmica, não se percebe uma regra de escrita em SW, entretanto um sinal pode ser escrito em SW com até dois movimentos de dinâmica. Nesse caso, um movimento é alocado abaixo das CMs e o outro é alocado acima das CMs, como nos sinais PATINAR e ANDAR DE SALTO ALTO.

No sinal PATINAR, o componente - (uma mão se move a outra permanece imóvel), foi alocado abaixo das CMs levemente deslocadas; quanto ao componente (lento), foi alocado acima da linha do ombro. 
No sinal ANDAR DE SALTO ALTO o componente $\approx(M A)$, foi alocado abaixo das CMs levemente deslocadas; quanto ao componente - (lento), foi alocado acima das setas.

No sinal OLHAR RÁPIDO PARA A DIREITA, o componente - (rápido) foi alocado abaixo da seta. No sinal BATER, o componente (tenso) foi alocado abaixo da CM. Por fim, no sinal PREGUIÇA, o componente a (relaxado) foi alocado ao lado da seta.

Compreendemos que por esses detalhes e, para que a aprendizagem e compreensão de SW seja eficiente, necessário se faz pesquisa acerca da alocação dos componentes para os movimentos de dinâmica, principalmente em sinais escritos que envolvem a alocação de dois movimentos de dinâmica.

\section{Movimentos da cabeça}

Os movimentos da cabeça ocorrem para cima ou para baixo, para a esquerda ou para a direita (escrita com setas duplas), são feitas conforme o Quadro 19.

Quadro 19 - Movimentos da cabeça com setas de haste duplas

\begin{tabular}{|c|c|c|c|c|c|}
\hline Para cima & OQUE? & $\begin{array}{c}\text { Para cima e para } \\
\text { baixo }\end{array}$ & SIM & $\begin{array}{c}\text { Para a esquerda } \\
\text { e para a direita }\end{array}$ & NÃO \\
\hline
\end{tabular}

Fonte da escrita em SW: Barreto e Barreto (2012, p. 165).

Quando se apresentam com setas de haste simples, o movimento da cabeça ocorre para frente e para trás, conforme Quadro 20.

Quadro 20 - Movimentos da cabeça com setas de haste simples Movimento da cabeça para frente e para trás

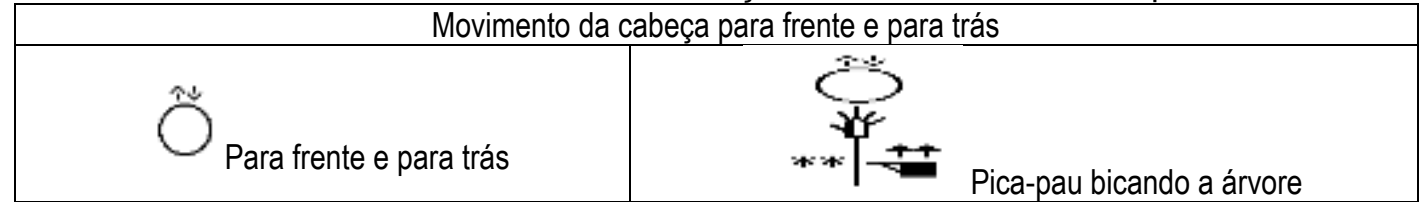

Fonte da escrita em SW: Barreto e Barreto (2012, p. 166). 
No Quadro 21, apresentam-se representações para a inclinação da cabeça.

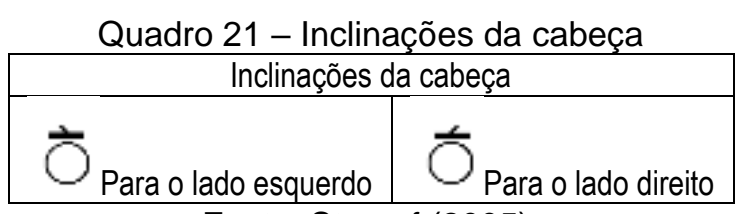

Fonte: Stumpf (2005).

Quanto aos demais movimentos da cabeça, sugerimos aprofundar a pesquisa em Barreto e Barreto (2012), Stumpf (2005) e Sutton (2003).

\section{Expressões não manuais - Expressões faciais em SW}

A testa, as sobrancelhas, a boca, os dentes, os lábios, a língua, os olhos e a bochecha, são alocados dentro de um círculo representativo da cabeça (BOUTORA 2003 apud STUMPF 2005; NOBRE, 2011). O círculo somente com preenchimento branco, de acordo com Barreto e Barreto (2012), representa a cabeça vista por trás. Nesse sentido, consideramos como cabeça, o círculo com fundo branco, e como cabeça/face, quando apresenta delimitação e/ou expressão facial.

Strobel (2008, p. 43) considera que as expressões facial e corporal são fundamentais na comunicação na LS, como um modo de emissão de mensagens, por contextos não decorrentes da oralidade, mas do corpo e da expressão da face que reforça e comunica uma ideia.

Identificamos que Capovilla, Raphael e Maurício (2009) alocam, em alguns sinais escritos, mais de duas expressões faciais na cabeça/face. Barreto e Barreto (2012) alocam até duas expressões faciais. No texto escrito em SW por Nobre (2011, p. 74), “A menina e o cão”, verificamos que o autor alocou, na maioria dos sinais escritos, até duas expressões faciais. No artigo escrito em SW "Tradução e Interpretação da Língua Brasileira de Sinais: Formação e Pesquisa", Stumpf e Quadros (1996) alocaram, no máximo, duas expressões faciais. Nesse sentido, consideramos que a alocação de uma e no máximo duas expressões 
faciais são suficientes para a compreensão de um sinal escrito que envolve ENM e/ou ponto de articulação na face.

Os Quadros 22, 23, 24, 25 e 26 mostram representações para expressões faciais de testa, sobrancelhas, boca, olhos e bochecha ${ }^{3}$.

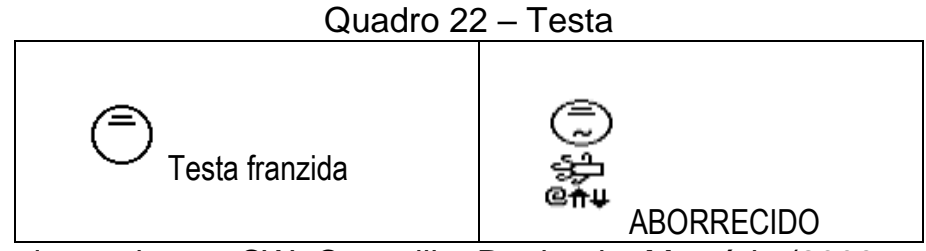

Fonte da escrita em SW: Capovilla, Raphael e Maurício (2009, p. 140).

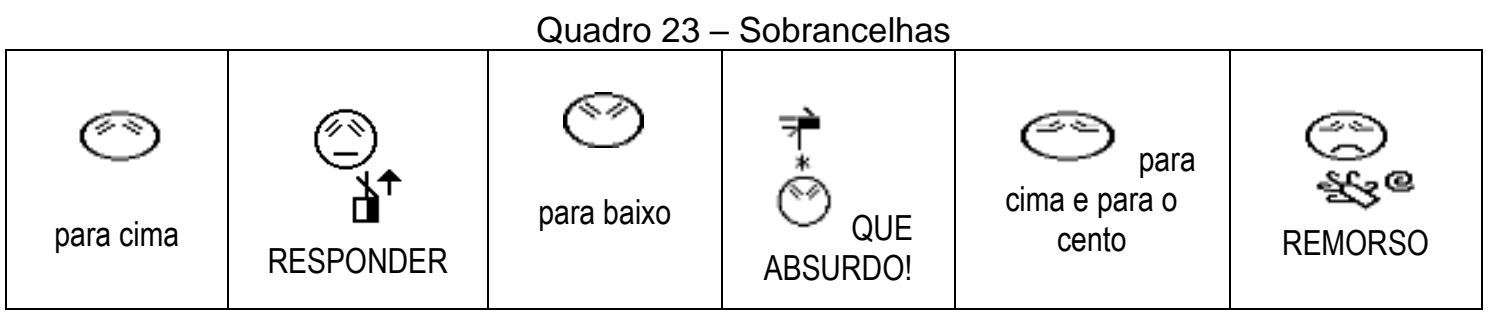

Fonte: Dados da pesquisa.

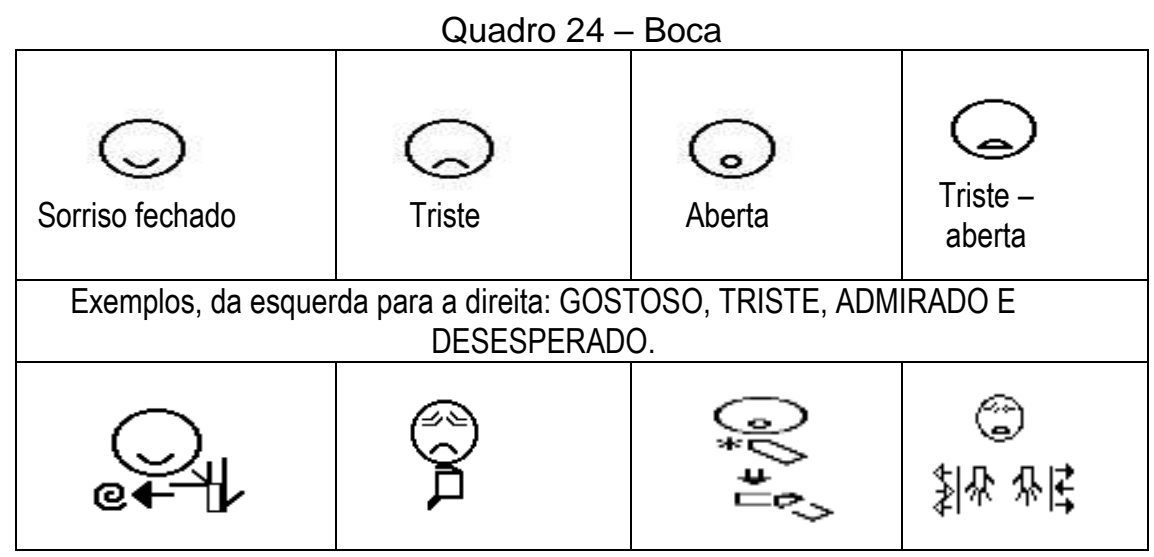

Fonte: Dados da pesquisa

\footnotetext{
${ }^{3}$ As expressões faciais para dentes, lábios e língua não serão abordadas neste artigo. As referidas expressões podem ser pesquisadas em Barreto e Barreto (2012, p. 196, 197 e 211), Stumpf (2005, p. 82) e Sutton (2003, p. 176 a 179).
} 
Quadro 25 - Olhos

\begin{tabular}{|c|c|c|}
\hline 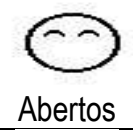 & 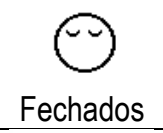 & Apertados \\
\hline $\begin{array}{c}\text { ※a } \\
\text { OLHOS }\end{array}$ & DEFUNTO & $\overbrace{\text { POUQUÍSSIMO }}^{\underset{\sim}{\boldsymbol{\sim}}}$ \\
\hline
\end{tabular}

Fonte: Dados da pesquisa.

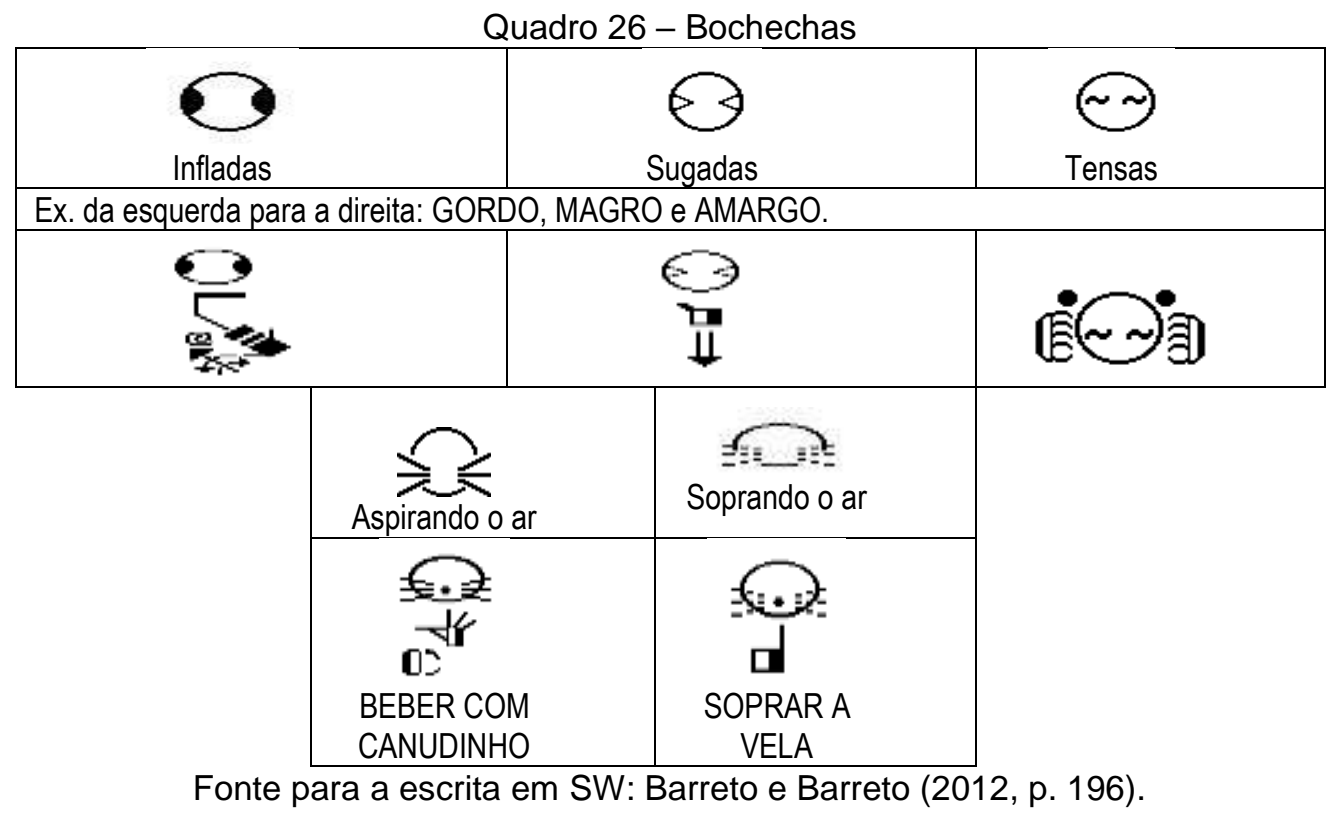

No Quadro 26, acima, elaborado com base em Barreto e Barreto (2012), Stumpf (2005) e Sutton (2003), encontramos diferenciação de denominação para a representação $\longleftrightarrow$. Barreto e Barreto (2012, p. 195) denominam de "bochechas infladas", Stumpf (2008, p. 23), Capovilla, Raphael e Maurício (2009, p. 1991) e Sutton (2003, p. 171) nomeiam de "bochechas estufadas". Quanto às demais denominações para a bochecha, não há variações.

Observa-se que, quando as bochechas estão infladas/estufadas, alocase, em cada lado da face, a delimitação com preenchimento preto $\longleftrightarrow$. Nas bochechas sugadas, aloca-se no lado esquerdo da face a delimitação > e no lado direito da face a delimitação <. Nas bochechas tensas, alocam-se na face duas linhas sinuosas $\Theta$. Na expressão facial aspirar o ar, aloca-se em cada lado da face, três linhas não pontilhadas $ミ$. Por fim, na expressão facial soprando o ar, alocam-se em cada lado da face três linhas pontilhadas 
Verifica-se, ainda, no Quadro 26, que as expressões faciais iniciam a escrita dos sinais GORDO, MAGRO, BEBER NO CANUDINHO e SOPRAR A VELA. Quanto à expressão facial do sinal AMARGO, foi alocada entre as CMs. Além destas expressões faciais apresentadas acima, há outras que podem ser pesquisadas nos referenciais teóricos deste artigo. Nesse sentido, abordaremos, a seguir, pontos de articulação ou locação.

\section{Pontos de articulação ou locação}

Consideraremos como ponto de articulação partes do corpo que há contato de uma ou das duas mãos. Há sinalizações em que a mão toca a cabeça, o pescoço, a face, os ombros e peito, os ombros, a sobrancelha, olhos, nariz e boca. Analisa-se que as sobrancelhas, olhos, o nariz e a boca, abordados acima como expressões faciais, também podem ser considerados como ponto de articulação. Procederemos a seguir com cada ponto de articulação citado.

\subsection{Cabeça}

Conforme abordado acima, Barreto e Barreto (2012, p. 56) representam a cabeça vista por trás como um círculo de fundo branco. Em sinais que envolve a locação na parte de trás da cabeça, duas linhas verticais curvas são alocadas nos lados direito e esquerdo do círculo: ${ }^{-\infty}$. Apresentam-se, no Quadro 27, três exemplos de sinal em que a CM toca a parte de trás da cabeça.

Quadro 27 - Sinais em que a mão toca a parte de trás da cabeça

\begin{tabular}{|c|c|c|}
\hline & \\
\hline $\begin{array}{c}\text { FALAR MAL DAS } \\
\text { PESSOAS }\end{array}$ & $\begin{array}{l}\text { IMPLANTE } \\
\text { COCLEAR }\end{array}$ & COSTAS \\
\hline
\end{tabular}

Fonte: Barreto e Barreto (2012, p. 56). 


\subsection{Pescoço}

A representação $Q$ é utilizada quando a locação do sinal ocorre no pescoço. Apesar de alocado abaixo da cabeça, o SignPuddle, disponível em $<$ www.signbank.org/signpuddle > permite a escrita somente da representação do pescoço: / I denominada, neste artigo, como duas linhas verticais curvas, distanciadas e paralelas. Tendo em vista que podemos escrever a representação do pescoço sem a cabeça vista por trás, provavelmente o sinal VONTADE possa vir a ser escrito com a supressão do círculo. No entanto, verifica-se no Quadro 24 que Capovilla, Raphael e Maurício (2009, p. 1863), Barreto e Barreto (2012, p. 134) e Sutton (2003, p. 104) escrevem o referido sinal em SW, com a alocação da cabeça, mesmo que haja clareza de que o ponto de articulação ocorre no pescoço.

Quadro 28 - Escrita do sinal VONTADE

\begin{tabular}{|l|l|l|}
\hline & & \\
\hline $\begin{array}{l}\text { Capovilla, Raphael e Maurício } \\
(2009)\end{array}$ & Barreto e Barreto (2012) & (Sutton, 2003). \\
\hline
\end{tabular}

Fonte: Capovilla, Raphael e Maurício (2009, p. 1863), Barreto e Barreto (2012, p. 134) e Sutton (2003, p. 104).

\subsection{Face}

Barreto e Barreto (2012, p. 74) compreendem que mediante a dificuldade de visualizar o local do toque da CM na face, esta se apresenta com semicírculo em locais estratégicos. As denominações das delimitações, constantes do Quadro 29, são proposições da autora. Podemos considerar que as referidas delimitações são possíveis para a esquerda e para a direita e para cima e para baixo. 
Quadro 29 - Algumas delimitações da face

(2)

Fonte da escrita em SW: Barreto e Barreto (2012, p. 74 e 77). ${ }^{4}$

\subsection{Ombros e peito}

Barreto e Barreto (2012, p. 73) compreendem que quando a mão toca o centro do peito, o contato é escrito abaixo da $\mathrm{CM}$ e não há necessidade de escrever o ombro - Capovilla, Raphael e Maurício (2009) preferem alocar o ombro para esses casos. O Quadro 30 apresenta à esquerda, exemplos de sinais escritos a inclusão e, à direita, os mesmos sinais escritos com a supressão do ombro.

Quadro 30 - Sinais escritos em que a mão toca o centro do peito, à esquerda, com a alocação do ombro e, à direita, sem alocação do ombro

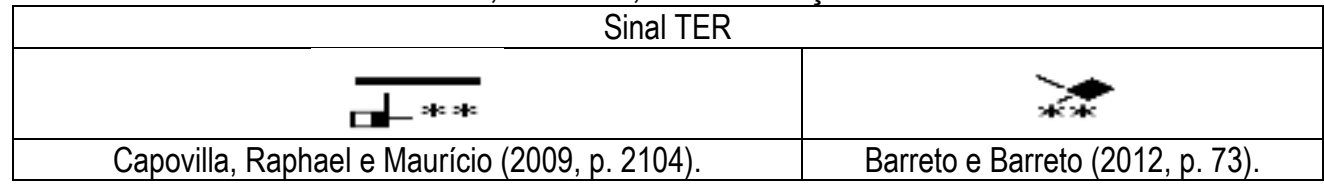

$$
\text { Fonte: Dados da pesquisa. }
$$

Em relação aos sinais em que a(s) mão(s) toca $(m)$ um ou os dois lados do peito ou do ombro, Barreto e Barreto (2012) sugerem a alocação da linha horizontal representativa do ombro, conforme se apresenta nos sinais NÚMERO, POLÍCIA e AMIGO, no Quadro 31.

${ }^{4} \mathrm{O}$ quadro foi elaborado com referencial de Stumpf (2014), Barreto e Barreto (2012), Capovilla, Raphael e Maurício (2009) e Sutton (2003). 
Quadro 31 - Alocação do ombro nos sinais em que a mão toca um ou os dois lados do peito

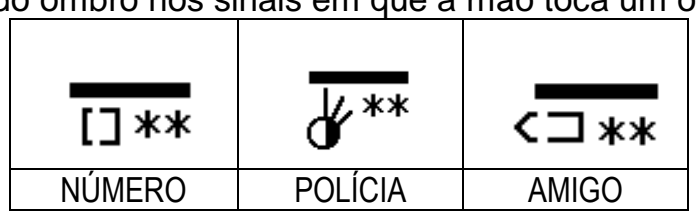

Fonte da escrita em SW: Barreto e Barreto (2012, p. 74).

\subsection{Sobrancelha}

Barreto e Barreto (2012) compreendem a sobrancelha como locação quando a articulação do sinal nela ocorre. Nesse caso, são alocadas duas linhas horizontais paralelas na face (círculo). No Quadro 32, à direita, a representação da sobrancelha como locação e, no lado esquerdo, o sinal escrito em SW.

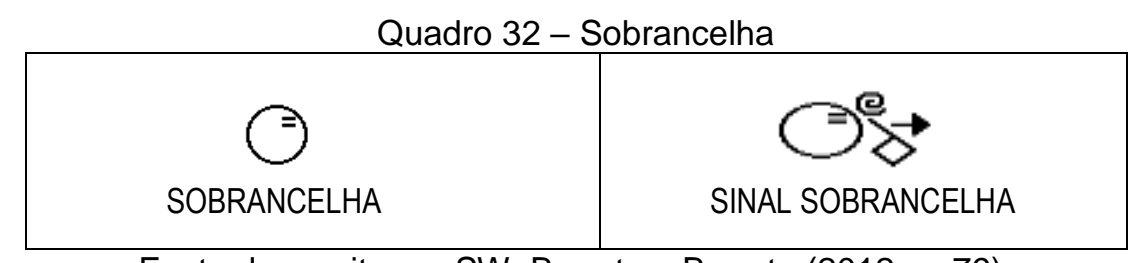

Fonte da escrita em SW: Barreto e Barreto (2012, p. 79).

\subsection{Olhos}

Em alguns sinais da Libras, os olhos são ponto de articulação ou locação. Barreto e Barreto (2012) os representam com dois semicírculos alocados na face (círculo), quando o sinal envolve os dois olhos, ou um semicírculo alocado na cabeça/face, quando envolve apenas um olho, conforme Quadro 33.

\section{Quadro 33 - Olho(s)}

\begin{tabular}{|c|c|c|c|}
\hline 2 olhos abertos & Ex. OLHOS & 1 olho aberto & Ex. VER \\
\hline$\rightarrow$ & \&a & &
\end{tabular}

Fonte da escrita em SW: Barreto e Barreto (2012, p. 79). 


\subsection{Nariz}

Stumpf (2014), Barreto e Barreto (2012), Capovilla Raphael e Maurício (2009) e Sutton (2003) afirmam que para os sinais da Libras em que o contato seja realizado no nariz ou próximo a ele, uma linha vertical (representação do nariz) deve ser alocada, centralizada na face. No Quadro 34, apresenta-se a representação do nariz, com exemplos da escrita em SW.

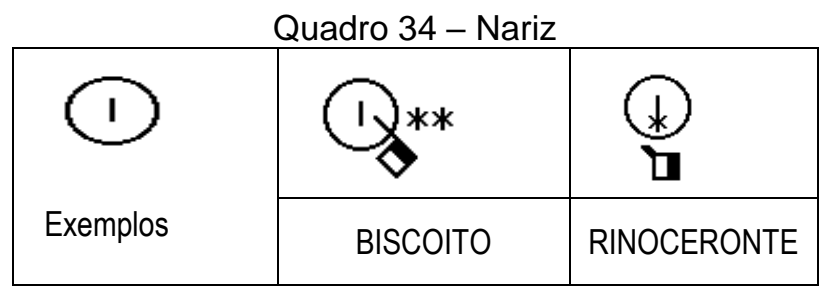

Fonte: Dados da pesquisa.

\subsection{Boca}

Barreto e Barreto (2012, p. 80) sugerem que, quando a mão toca ou se aproxima da boca, utiliza-se este círculo com uma linha horizontal $\ominus$, ou seja, a cabeça/face com uma linha horizontal alocada (a boca). Galea (2014, p. 659) denominou esta representação de "boca fechada (neutra)." Verificam-se no Quadro 35, exemplos de sinais articulados na boca.

Quadro 35 - Boca como locação ${ }^{5}$

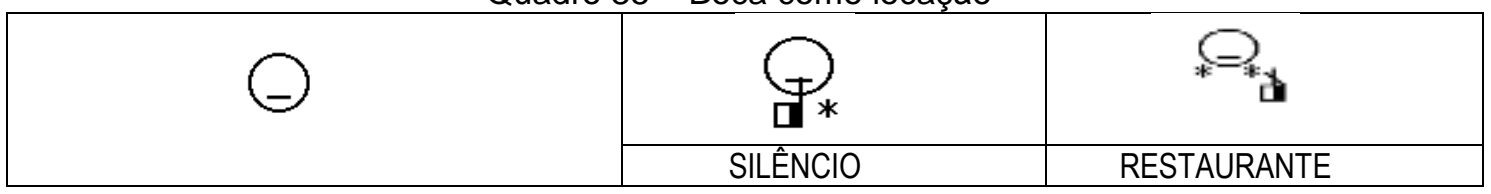

Fonte: Dados da pesquisa.

\section{Alfabeto manual}

Quadros e Karnopp (2004, p. 88) indicam que a comunicação na língua de sinais envolve a soletração de palavras da língua portuguesa para uma

\footnotetext{
5 Idem.
} 
variedade de contextos, ou seja, para as palavras técnicas que não possuem o sinal equivalente, para indicar o assunto, o título a que se faz referência e para nomes próprios. Para essas autoras, a soletração manual é uma representação da ortografia da língua falada ou escrita e envolve uma sequência de configurações de mãos que corresponde à sequência de letras das palavras escritas da língua portuguesa. Battison (1978 apud QUADROS; KARNOPP, 2004, p. 88) considera que palavras da língua portuguesa podem ser emprestadas à língua brasileira de sinais. Com base neste referencial teórico, apresentamos abaixo, no Quadro 36, o alfabeto em SW, utilizado na soletração manual ou datilologia.

Quadro 36 - Alfabeto manual em SW

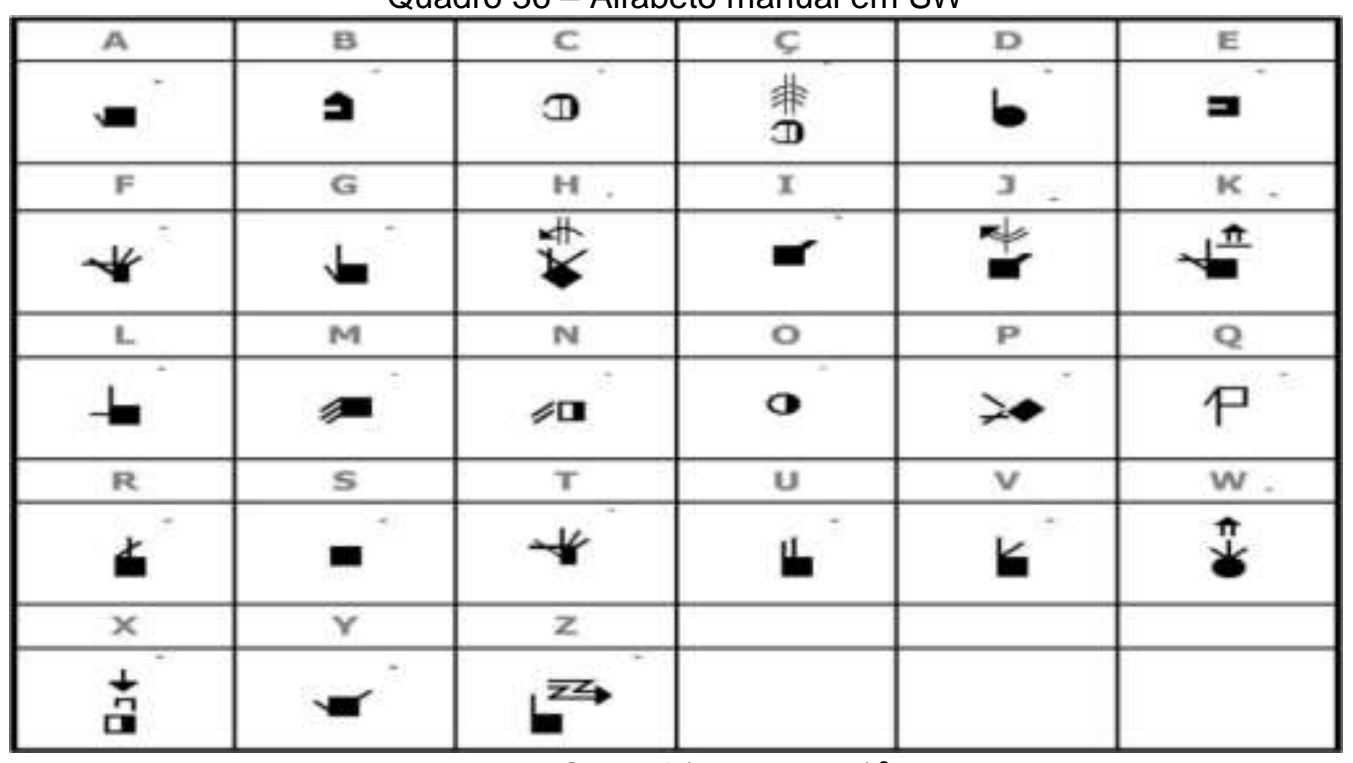

Fonte: Stumpf $\left(2014\right.$, p. 32) ${ }^{6}$.

A seguir, apresentamos a escrita em SW para nomes próprios, elaborada pela autora, conforme o quadro acima.

\section{T) C-A-R-L-A

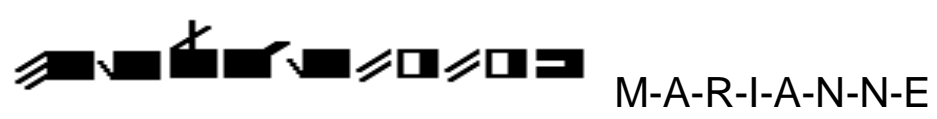

\footnotetext{
${ }^{6}$ Há diferenciações entre o alfabeto manual apresentado nesta tese e o alfabeto manual de Barreto e Barreto (2012, p. 132).
} 


\section{Considerações finais}

Este artigo realizou uma abordagem preliminar do SW como alternativa de registro para a escrita da língua de sinais que se realiza em sequência espacial vertical. Devido à abrangência do sistema, o artigo abordou a perspectiva expressiva, as configurações de mãos básicas, alguns movimentos, dinâmicas de movimentos, algumas expressões não manuais, alguns pontos de articulação e o alfabeto manual.

Com o referencial teórico de Capovilla, Raphael e Maurício (2009), Sutton (2001), Stumpf (2008) e Barreto e Barreto (2012) foram identificadas denominações para os quiremas apresentados como também exemplos da escrita.

Nesse sentido, contribuímos para a divulgação do sistema visando à consolidação de SW como escrita para a língua de sinais.

\section{Referências}

BARRETO, M.; BARRETO, R. Escrita de sinais sem mistérios. Belo Horizonte: Ed. do Autor, 2012.

BIANCHINI, C. S. Analyse métalinguistique de l'émergence d'un système d'écriture des Langues des Signes: SignWriting et son application à la Langue des Signes Italienne (LIS). 512p. Université de Paris VIII - Vincenne SaintDenis. École Doctorale Cognition, Langage et Interaction. Doctorat en Sciences du Langage. Soutenue, 2012, 512p.

CAPOVILLA, F. C.; RAPHAEL, W. D. Dicionário enciclopédico ilustrado trilíngue da língua de sinais brasileira. São Paulo: Edusp, 2001.

CAPOVILLA, F. C. et al. O desafio do bilinguismo na educação de surdos: descontinuidade entre a língua de sinais e a escrita alfabética e estratégias para resolvê-la. In: CAPOVILLA, F. C. (org.). Neuropsicologia e aprendizagem: uma abordagem multidisciplinar. São Paulo: Memnon, 2004.

CAPOVILLA, F. C.; RAPHAEL, W. D; MAURÍCIO, A. C. L. Novo Deit-Libras: Dicionário enciclopédico ilustrado trilíngue da língua de sinais brasileira (Libras) baseado em Linguística e Neurociências Cognitivas. vol. I (Sinais de A a H), vol. II (Sinais de L a Z). São Paulo: Editora da Universidade de São Paulo; Inep; CNPq; Capes, 2009. 
GALEA, M. SignWriting (SW) of Malartigo Sign Language (LSM) and its development into an orthography: linguistic considerations. 689f. Tese (Doutorado em Linguística) - Institute of Linguistics, University of Malta, Malta 2014.

NOBRE, R. S. Processo de grafia da língua de sinais: uma análise fonomorfológica da escrita em SignWriting. 189f. Dissertação (Mestrado em Linguística Aplicada). Florianópolis: UFSC, 2011.

QUADROS, R. M.; KARNOPP, L. B. Língua brasileira de sinais: estudos linguísticos. Porto Alegre: Artmed. 2004.

QUADROS, R. M.; STUMPF, M. R. Tradução e Interpretação de Língua Brasileira de Sinais: Formação e Pesquisa. Cadernos de Tradução, Florianópolis, n. 26. p. 165-206, 2010/2.

STROBEL, K. L. As imagens do outro sobre a cultura surda. Florianópolis: Ed. UFSC, 2008.

STUMPF, M. R. Aprendizagem de escrita de língua de sinais pelo sistema signwriting: línguas de sinais no papel e no computador. 330f. Tese (Doutorado em Informática na Educação) - Universidade Federal do Rio Grande do Sul, Porto Alegre: UFRGS, 2003.

STUMPF, M. R. Escrita de Sinais III - Texto Base. Ementa da disciplina do curso Letras/Libras. UFSC. Florianópolis, 2008.

STUMPF, M. R. Material didático para a disciplina Escrita de Sinais III. UFSC. Florianópolis, 2014.

SUTTON, V. Lições sobre o SignWriting: um sistema de escrita para língua de sinais. Tradução: Marianne Stumpf e Antonio C. da Rocha Costa. s.d. Disponível em: http://rocha.c3.furg.br/arquivos/download/licoes-sw.pdf. Acesso em: 20 maio 2011. 